\title{
Preoperative proteinuria is associated with increased rates of acute kidney injury after partial nephrectomy
}

Önder Kara ${ }^{1,2}$, Matthew J. Maurice ${ }^{1}$, Pascal Mouracade ${ }^{1}$, Ercan Malkoc ${ }^{1}$, Julien Dagenais ${ }^{1}$, Mustafa Çapraz ${ }^{3}$, Jaya S. Chavali ${ }^{1}$, Merve Yazici Kara ${ }^{4}$, Jihad H. Kaouk ${ }^{1}$

${ }^{1}$ Department of Urology, Glickman Urological and Kidney Institute, Cleveland Clinic, Cleveland, OH, USA;

${ }^{2}$ Kocaeli University, Medical School, Kocaeli, Turkey; ${ }^{3}$ Amasya University, Medical School, Amasya, Turkey; ${ }^{4}$ Kocaeli Derince Training and Research Hospital, Kocaeli, Turkey

\section{ABSTRACT}

Purpose: We investigated the association between preoperative proteinuria and early postoperative renal function after robotic partial nephrectomy (RPN).

Patients and Methods: We retrospectively reviewed 1121 consecutive RPN cases at a single academic center from 2006 to 2016. Patients without pre-existing CKD (eGFR $\geq 60$ $\mathrm{mL} / \mathrm{min} / 1.73 \mathrm{~m}^{2}$ ) who had a urinalysis within 1 -month prior to RPN were included. The cohort was categorized by the presence or absence of preoperative proteinuria (trace or greater $(\geq 1+)$ urine dipstick), and groups were compared in terms of clinical and functional outcomes. The incidence of acute kidney injury (AKI) was assessed using RIFLE criteria. Univariate and multivariable models were used to identify factors associated with postoperative AKI.

Results: Of 947 patients, 97 (10.5\%) had preoperative proteinuria. Characteristics associated with preoperative proteinuria included non-white race $(\mathrm{p}<0.01)$, preoperative diabetes $(\mathrm{p}<0.01)$ and hypertension $($ HTN) $(\mathrm{p}<0.01)$, higher ASA $(\mathrm{p}<0.01)$, higher BMI $(p<0.01)$, and higher Charlson score $(p<0.01)$. The incidence of AKI was higher in patients with preoperative proteinuria $(10.3 \%$ vs. $4.6 \%, \mathrm{p}=0.01)$. The median eGFR preservation measured within one month after surgery was lower ( $83.6 \%$ vs. 91\%, $p=0.04$ ) in those with proteinuria; however, there were no significant differences by 3 months after surgery or last follow-up visit. Independent predictors of AKI were high BMI $(\mathrm{p}<0.01)$, longer ischemia time $(\mathrm{p}<0.01)$, and preoperative proteinuria $(\mathrm{p}=0.04)$.

Conclusion: Preoperative proteinuria by urine dipstick is an independent predictor of postoperative AKI after RPN. This test may be used to identify patients, especially those without overt CKD, who are at increased risk for developing AKI after RPN.

\section{ARTICLE INFO}

Önder Kara

https://orcid.org/0000-0003-1197-2932

\section{Keywords:}

Kidney Neoplasms; Proteinuria;

Acute Kidney Injury

Int Braz J Urol. 2019; 45: 932-40

Submitted for publication:

November 22, 2018

Accepted after revision:

January 13, 2019

Published as Ahead of Print:

March 20, 2019

\section{INTRODUCTION}

Partial nephrectomy (PN) is the gold standard treatment for T1a, and when technically feasible $\mathrm{T} 1 \mathrm{~b}$ renal masses, due to improved renal functional preservation (1). Given the benefits offered by the robotic platform, there has been an upward trend in the utilization of robotic partial nephrectomy (RPN) for the treatment of renal masses, and relatedly robotic adoption has increased the overall utilization of nephron-sparing surgery $(2,3)$. PN reduces the amount of renal parenchymal volume loss, more so when performed robotically; however; it does not eli- 
minate nephron loss entirely (4-6). Furthermore, the remaining kidney may experience ischemic damage as a result of the temporary vascular clamping required during PN (5). Acute kidney injury (AKI) is associated with increased hospital length of stay and in hospital mortality (7), and following AKI patients have an increased risk of residual structural and functional disease (8). Therefore, preoperative prediction of AKI, especially for patients with presumed normal renal function (Estimated Glomerular Filtration Rate (eGFR) $>60$ ) is difficult, and important in patients' counseling.

The glomerular filtration rate (GFR) has been used for a long time as the primary indicator in diagnosing and staging CKD (9). However, Kidney Disease Improving Global Outcomes (KDIG0) recently included etiology, eGFR, and proteinuria as vital components for CKD identification, as each of them has a prognostic value on survival and renal function stability in the population (10-12). The association between CKD severity and AKI risk after PN was quantified based on one component of KDIGO classification (as measured by levels of estimated GFR) in previously published series (13-15). Our primary objective was to assess proteinuria as a marker of early renal dysfunction in patients undergoing RPN.

\section{PATIENTS AND METHODS}

Using our institutional review board-approved database, we abstracted data on 1121 RPN cases performed at our center from 2006 to 2016. Patients without pre-existing CKD (eGFR $\geq 60$ $\mathrm{mL} / \mathrm{min} / 1.73 \mathrm{~m}^{2}$ ) who had a urinalysis within 1 -month prior to RPN were included in the study $(\mathrm{n}=947)$. The cohort was categorized by the presence or absence of preoperative proteinuria, and groups were compared in terms of clinical and functional outcomes. The incidence of AKI was assessed using RIFLE criteria. Univariate and multivariable models were used to identify factors associated with postoperative AKI.

\section{Definition of proteinuria}

Urine dipstick analysis was used to detect proteinuria. Proteinuria was defined as presence (trace or greater $(\geq 1+)$ urine dipstick), and absence (negative urine dipstick).

\section{Definition of AKI}

The diagnosis of AKI was based on RIFLE criteria (16). Grade 1 (risk) is characterized by a 1.5-2.0-fold increase in serum creatinine or urine output (UO) $<0.5 \mathrm{~mL} / \mathrm{kg} / \mathrm{h}$ for 6 hours; grade 2 (injury) is characterized by a $2.0-3.0$-fold increase in serum creatinine or UO $0.5 \mathrm{~mL} / \mathrm{kg} / \mathrm{h}$ for 12 hours; grade 3 (failure) is characterized by any increase $>3.0$-fold in serum creatinine, temporary need for dialysis, UO $<0.3 \mathrm{~mL} / \mathrm{kg} / \mathrm{h}$ for 12 hours, or anuria for 12 hours. There were no cases of renal loss or end-stage renal failure in this cohort of patients.

\section{Study variables}

Demographic and tumor characteristics included patient age; race (white and non-white); gender; body mass index (BMI); Charlson Comorbidity Index (CCI); American Society of Anesthesiology (ASA) score; history of preoperative diabetes mellitus (DM), hypertension (HTN), and/or smoking; preoperative estimated glomerular filtration rate (eGFR); solitary kidney status; tumor size; R.E.N.A.L. score; and tumor pathology (benign or malignant). Intraoperative variables included operative time, ischemia time, estimated blood loss (EBL), and intraoperative transfusion. Postoperative variables included 30-day postoperative complications, length of hospital stay, and 30-day readmissions. Complications were graded using the Clavien-Dindo classification system (17) and were characterized as minor (Clavien 1-2) and major (Clavien 3-5). Tumor complexity was assessed based on the R.E.N.A.L nephrometry classification system (18). Functional outcomes were assessed using eGFR, which was calculated using the modification of diet in renal disease (MDRD) formula (19). eGFR preservation was defined as follow-up postoperative eGFR divided by baseline eGFR $\mathrm{x}$ 100. CKD upstaging was defined as any increase in CKD stage (20) from the time of preoperative assessment to the time of latest postoperative follow-up.

\section{Surgical technique}

We used our standard RPN technique as described previously (21). The transperitoneal 
approach was used in all cases. Intraoperative ultrasound was used routinely for intraoperative tumor identification and surgical planning. Intracorporeal renal parenchymal cooling was used selectively when ischemia times were expected to be greater than 25 minutes.

\section{Study outcomes}

The primary outcome was postoperative AKI. AKI was assessed using RIFLE criteria. Univariate and multivariable models were used to identify factors associated with postoperative AKI. Secondary outcomes included operative time, EBL, ischemia time, perioperative transfusion, length of hospital stay, 30day readmission, overall and major complications.

\section{Statistical analysis}

Continuous variables, presented as mean \pm standard deviation (SD) if normally distributed or as median (interquartile range (IQR)) if non-normally distributed, were compared using the t-test or Mann-Whitney U test, respectively. Categorical variables were compared using the chi-squared test. Multivariable analysis was conducted using logistic regression to identify independent predictors of postoperative AKI. Significance was set at $\mathrm{p}<0.05$. Analyses were performed using SPSS v24 software (IBM SPSS Statistics, Armonk, NY: IBM Corp).

\section{RESULTS}

In the final cohort, 947 patients were included. Preoperative proteinuria was observed in $97(10.5 \%)$ patients on urine dipstick. Of these, $18(18.5 \%)$ had trace $(<30 \mathrm{mg} / \mathrm{dL}), 78(80.4 \%)$ had 30 to $299 \mathrm{mg} / \mathrm{dL}$, and $1(1.1 \%)$ had $>300 \mathrm{mg} /$ $\mathrm{dL}$ urinary protein preoperatively. Characteristics associated with preoperative proteinuria included non-white race $(\mathrm{p}<0.01)$, pre-existing $\mathrm{DM}(\mathrm{p}<0.01)$, pre-existing HTN $(\mathrm{p}<0.01)$, higher BMI $(\mathrm{p}<0.01)$, higher ASA $(\mathrm{p}<0.01)$, and higher Charlson score $(p<0.01)$. Tumor characteristics, including mass size $(\mathrm{p}=0.08)$, R.E.N.A.L score $(\mathrm{p}=0.13)$, and malignant disease $(\mathrm{p}=0.06)$, were not associated with preoperative proteinuria (Table-1).

Postoperative AKI was more prevalent in patients with preoperative proteinuria $(10.3 \%$ vs. $4.6 \%, p=0.01)$. The median eGFR preservation measured within one month after surgery was lower (83.6 (73.3-89.8) \% vs. 91 (79-101) \%, $\mathrm{p}=0.04$ ) in those with proteinuria; however, there were no significant differences by 3 months after surgery (88 (77.3-98.4) \% vs. 89 (78.2-97.5) \%, $\mathrm{p}=0.9$ ) or last follow-up visit (85.1 (72.9-96.2) \% vs. 86.9 (76.1-98.2) \%, p=0.2). Likewise, the prevalence of CKD upstaging at the latest follow-up (19.5 vs. 18.7 months, $p=0.56$ ) did not differ between groups ( $43.3 \%$ vs. $42.1 \%, \mathrm{p}=0.82$ ) (Table-2).

In terms of secondary outcomes, there were no significant differences in intraoperative variables, including operative time, EBL, ischemia time, and intraoperative blood transfusion between the two groups. However, proteinuria was associated with higher rates of overall $(26.8 \%$ vs. $16.8, \mathrm{p}=0.01$ ) and major (9.3\% vs. $4.6 \%, \mathrm{p}=0.04$ ) postoperative complications and 30-day readmissions (Table-3).

On further analysis of postoperative complications, the specific complications, which contributed to the disparity in complication rates between groups, included postoperative cardiac complications ( $7.2 \%$ vs. 2.6, $p=0.02$ ), and haemorrhagic complications necessitating selective arterial angioembolisation ( $4.1 \%$ vs. $0.9 \%, p=0.02$ ) (Table-4).

On multivariable logistic regression, after adjusting for BMI, CCI, preoperative proteinuria, tumor size, baseline eGFR, and ischemia time, significant predictors of postoperative AKI included higher BMI (OR 1.07, 95\% CI 1.03-1.17, $\mathrm{p}<0.01$ ), ischemia time $>20$ min (OR 4.86, 95\% CI 2.1411.01) $\mathrm{p}<0.01$ ), and preoperative proteinuria (OR 2.4, 95\% CI 1.02-5.65, $\mathrm{p}=0.04$ ) (Table-5).

\section{DISCUSSION}

Despite the nephron-sparing benefits of PN, 4.9\% of patients undergoing PN experience postoperative AKI (15). In turn, AKI is associated with increased morbidity and mortality (22). While preexisting CKD is one of the most common risk factor for postoperative AKI after PN, even patients with normal preoperative renal function are at risk for postoperative AKI (23). However, at present, these at-risk patients without CKD are not 
Table 1 - Patient demographic and tumor characteristics.

\begin{tabular}{|c|c|c|c|}
\hline \multirow[t]{2}{*}{ Variables } & \multicolumn{2}{|c|}{ Proteinuria } & \multirow[t]{2}{*}{$P$ value } \\
\hline & $\begin{array}{c}\text { Yes } \\
\mathrm{N}=97(10.5 \%)\end{array}$ & $\begin{array}{c}\text { No } \\
\mathrm{N}=850(89.5 \%)\end{array}$ & \\
\hline Age years, $( \pm S D)$ & $57.1(12.7)$ & $57.7(12)$ & 0.79 \\
\hline Gender & & & 0.11 \\
\hline Male, n (\%) & $65(67)$ & $499(58.7)$ & \\
\hline Female, $n(\%)$ & $32(33)$ & $351(41.3)$ & \\
\hline Race & & & $<0.01$ \\
\hline White, $\mathrm{n}(\%)$ & $75(77.3)$ & $756(89)$ & \\
\hline Non-White, n (\%) & $22(22.7)$ & $144(11)$ & \\
\hline BMI, med (IQR) & $31.2(26.2-37)$ & $29.3(25.8-33.5)$ & 0.04 \\
\hline ASA, med (IQR) & $3(3-3)$ & $3(2-3)$ & $<0.01$ \\
\hline $\mathrm{CCl}$, med (IQR) & $1(0-2)$ & $0(0-1)$ & $<0.01$ \\
\hline Diabetes Mellitus, $n(\%)$ & $29(29.9)$ & $154(18.1)$ & $<0.01$ \\
\hline Hypertension, $\mathrm{n}(\%)$ & $64(66)$ & $451(53.1)$ & 0.01 \\
\hline Smoker, n (\%) & $13(13.4)$ & $123(14.5)$ & 0.77 \\
\hline Pre-Op eGFR, med (IQR) & $87.2(71.3-102.2)$ & $88.5(76-100.5)$ & 0.58 \\
\hline Solitary kidney, n (\%) & $3(3.1)$ & $13(1.5)$ & 0.22 \\
\hline Tumor size on CT cm, med (IQR) & $3.4(2.2-4.4)$ & $3(2.1-4)$ & 0.08 \\
\hline R.E.N.A.L score, med (IQR) & $8(6-9)$ & $7(6-9)$ & 0.13 \\
\hline Malignant disease, $n(\%)$ & $86(88.7)$ & $682(80.2)$ & 0.06 \\
\hline
\end{tabular}

$\mathbf{B M I}=$ Body mass index $\mathbf{C} \mathbf{C I}=$ Charlson comorbidity index; $\mathbf{C K D}=$ Chronic kidney disease; $\mathbf{C T}=$ Computed tomography; $\mathbf{E B L}=$ Estimated blood loss; $\mathbf{e G F R}=$ Estimated glomerular filtration rate; $\mathbf{I Q R}=$ Interquartile range; $\mathbf{O P N}=$ Open partial nephrectomy; $\mathbf{R P N}=$ Robotic partial nephrectomy; $\mathbf{S D}=$ Standard deviation

readily identifiable. Thus, there is a need for better tools to identify such patients who are more likely to experience AKI after PN.

Proteinuria has been identified as an essential component of renal dysfunction based on the most recent KDIGO guidelines (12) and appears to be a significant and independent predictor of overall survival and recurrence free survival in patients undergoing renal cancer surgery (24). Therefore, we hypothesized that preoperative proteinuria may be associated with postoperative AKI.

In this retrospective study, the prevalence of postoperative AKI was 5.1\%. Some studies have reported postoperative AKI rates after PN ranging from $0.8 \%$ to $10 \%(13,15,25)$ varying by institution, technique, approach, data collection, and AKI criteria. In our study, we used the RIFLE classification scheme for AKI, which is generally accepted for use in the PN population (24).

We found that proteinuria was an independent risk factor for AKI in non-CKD patients undergoing PN. Patients with proteinuria had 2.4-fold higher odds of AKI than patients without proteinuria. These results are consistent with prior studies that have shown an association between proteinuria and AKI after non-renal (26-28), and renal surgeries (29). Surprisingly, in our study, pre- 
Table 2 - Follow-up functional data.

\begin{tabular}{|c|c|c|c|}
\hline \multirow[t]{2}{*}{ Variables } & \multicolumn{2}{|c|}{ Proteinuria } & \multirow[t]{2}{*}{$P$ value } \\
\hline & $\begin{array}{c}\text { Yes } \\
\mathrm{N}=97(10.5 \%)\end{array}$ & $\begin{array}{c}\text { No } \\
\mathrm{N}=850(89.5 \%)\end{array}$ & \\
\hline \multicolumn{4}{|c|}{ Early postoperative functional outcomes (Primary Outcomes) } \\
\hline Acute kidney injury (RIFLE), $\mathrm{n}(\%)$ & $10(10.3)$ & $39(4.6)$ & 0.01 \\
\hline Risk (R) & $9(9.3)$ & $35(4.1)$ & \\
\hline Injury (I) & $1(1)$ & $4(0.5)$ & \\
\hline $\begin{array}{l}\text { Within } 1 \mathrm{mo} \text {. eGFR, } \mathrm{mL} / \mathrm{min} / 1.73 \mathrm{~m}^{2} \text {, median } \\
\text { (IQR) }\end{array}$ & $73(63-90)$ & $80(69-98)$ & 0.02 \\
\hline $\begin{array}{l}\text { Within } 1 \text { mo. \% eGFR preservation, median } \\
\text { (IQR) }\end{array}$ & $83.6(73.3-89.8)$ & $91(79-101)$ & 0.04 \\
\hline \multicolumn{4}{|l|}{ Late postoperative functional outcomes } \\
\hline 3-mo. eGFR, mL/min/1.73 m², median (IQR) & $76(61-94.9)$ & $77(65.3-91.8)$ & 0.98 \\
\hline 3-mo. \% eGFR preservation, median (IQR) & $88(77.3-98.4)$ & $89(78.2-97.5)$ & 0.9 \\
\hline Follow up times, months, median (IQR) & $19.5(6.2-29.4)$ & $18.7(5.7-38.4)$ & 0.56 \\
\hline Latest eGFR, mL/min/1.73 m², median (IQR) & $72(61.1-89.1)$ & $76(64.3-90.4)$ & 0.12 \\
\hline $\begin{array}{l}\text { Latest follow up \% eGFR preservation, median } \\
\text { (IQR) }\end{array}$ & $85.1(72.9-96.2)$ & $86.9(76.1-98.2)$ & 0.2 \\
\hline CKD upstaging at last follow-up, $\mathrm{n}(\%)$ & $42(43.3)$ & $358(42.1)$ & 0.82 \\
\hline
\end{tabular}

IQR = Interquartile range; $\mathbf{S D}=$ Standard deviation

Table 3 - Secondary outcomes.

\begin{tabular}{|c|c|c|c|}
\hline \multirow[t]{2}{*}{ Variables } & \multicolumn{2}{|c|}{ Proteinuria } & \multirow[t]{2}{*}{$P$ value } \\
\hline & $\begin{array}{c}\text { Yes } \\
\mathrm{N}=97(10.5 \%)\end{array}$ & $\begin{array}{c}\text { No } \\
\mathrm{N}=850(89.5 \%)\end{array}$ & \\
\hline \multicolumn{4}{|l|}{ Intraoperative outcomes } \\
\hline Operation time, min, mean $( \pm S D)$ & $182(48.8)$ & $180(53)$ & 0.34 \\
\hline EBL, mL., med (IQR) & $150(100-300)$ & $150(100-250)$ & 0.92 \\
\hline Ischemia time, min, mean $( \pm S D)$ & $20.8(10)$ & $20.3(10.1)$ & 0.68 \\
\hline Intraoperative transfusion, $\mathrm{n}(\%)$ & $2(2.1)$ & $7(0.8)$ & 0.23 \\
\hline \multicolumn{4}{|l|}{ Perioperative outcomes } \\
\hline Length of stay, days, med, (IQR) & $3(2-4)$ & $3(2-4)$ & 0.23 \\
\hline 30-day readmission, $n(\%)$ & $8(8.2)$ & $31(3.6)$ & 0.03 \\
\hline Postoperative transfusion, $\mathrm{n}(\%)$ & $2(2.2)$ & $48(5.9)$ & 0.22 \\
\hline Overall C. (Clavien-Dindo 1-5), n (\%) & $26(26.8)$ & $143(16.8)$ & 0.01 \\
\hline Major C. (Clavien-Dindo 3-5), n (\%) & $9(9.3)$ & $39(4.6)$ & 0.04 \\
\hline
\end{tabular}


Table 4 - Summary of complications based on preoperative proteinuria.

\begin{tabular}{|c|c|c|c|}
\hline \multirow[b]{2}{*}{ Complication type, \% (n) } & \multicolumn{2}{|c|}{ Proteinuria } & \multirow[t]{2}{*}{$P$ value } \\
\hline & $\begin{array}{c}\text { Yes } \\
\mathrm{N}=97(10.5 \%)\end{array}$ & $\begin{array}{c}\text { No } \\
\mathrm{N}=850(89.5 \%)\end{array}$ & \\
\hline Overall complications & $26(26.8)$ & $143(16.8)$ & 0.01 \\
\hline Major (Clavien-Dindo 3-5) & $9(9.3)$ & $39(4.6)$ & 0.04 \\
\hline Cardiac complications & $7(7.2)$ & $22(2.6)$ & 0.02 \\
\hline Myocardial infarction & $1(1)$ & $0(0)$ & \\
\hline Arrhythmia & $4(4.1)$ & $16(1.9)$ & \\
\hline Other cardiac & $2(2.1)$ & $6(0.7)$ & \\
\hline Pulmonary complications & $4(4.1)$ & $51(6)$ & 0.64 \\
\hline Pneumonia & $1(1)$ & $9(1.1)$ & \\
\hline DVT/PE & $1(1)$ & $11(1.3)$ & \\
\hline Other pulmonary & $2(2.1)$ & $31(3.6)$ & \\
\hline Genitourinary complications & $3(3.1)$ & $13(1.5)$ & 0.22 \\
\hline UTI & $2(2.1)$ & $4(0.5)$ & \\
\hline Urine leak & $1(1)$ & $9(1.1)$ & \\
\hline Gastrointestinal complications & $5(5.2)$ & $32(3.8)$ & 0.41 \\
\hline Clostridium difficil infection & $1(1)$ & $1(0.1)$ & \\
\hline Ileus/small bowel obstruction & $3(3.1)$ & $29(3.4)$ & \\
\hline Other gastrointestinal & $1(1)$ & $2(0.2)$ & \\
\hline Wound complications & $2(2.1)$ & $18(2.1)$ & 1 \\
\hline Surgical site infection & $0(0)$ & $13(1.5)$ & \\
\hline Hernia & 0 & $3(0.4)$ & \\
\hline Other wound & $2(2.1)$ & $2(0.2)$ & \\
\hline Neurologic complications & 0 & $2(0.2)$ & 1 \\
\hline Bleeding complications & $9(6.3)$ & $11(14.1)$ & \\
\hline Postop Transfusion & $2(2.1)$ & $48(5.6)$ & 0.22 \\
\hline Need for angioembolisation & $4(4.1)$ & $8(0.9)$ & 0.02 \\
\hline
\end{tabular}

operative proteinuria was not a predictor of long-term renal functional preservation. This finding contrasts a study by Krane et al. (30) and Bhindi et al. (29), and 0'Donnell et al. (31) which did show an association between proteinuria and long-term risk of CKD. It is possible that our follow up was not long enough to detect a difference in long-term functional outcomes.

Our findings suggest that proteinuria detected on urine dipstick is a good predictor of postoperative AKI in non-CKD patients. Urine dipstick is quick, inexpensive, and widely available, making it a good screening test. Preoperative assessment of proteinuria may help guide preoperative patient counseling, postoperative care, and medical treatment in non-CKD PN patients.

In addition to proteinuria, longer ischemia time and higher BMI were also independent risk factors for AKI. Our study demonstrated a 4.8-fold higher risk of AKI in patients with ischemia times longer than 20 minutes. The association between longer ischemia time and increased risk of post-PN 
Table 5 - Logistic regression analysis predicting AKI after PN.

\begin{tabular}{|c|c|c|c|c|c|c|}
\hline \multirow[t]{2}{*}{ Variables } & \multicolumn{3}{|c|}{ Univariate } & \multicolumn{3}{|c|}{ Multivariate } \\
\hline & $\mathrm{OR}$ & $95 \% \mathrm{Cl}$ & $\mathrm{P}$ & $\mathrm{OR}$ & $95 \% \mathrm{Cl}$ & $P$ \\
\hline Age (per year) & 0.99 & $0.97-1.01$ & 0.3 & & & \\
\hline \multicolumn{7}{|l|}{ Race } \\
\hline (White vs. Non-White) & 0.66 & $0.3-1.45$ & 0.4 & & & \\
\hline Gender (Male vs. Female & 1.01 & $0.56-1.82$ & 0.95 & & & \\
\hline $\mathrm{BMI}\left(\right.$ per $\left.\mathrm{kg} / \mathrm{m}^{2}\right)$ & 1.07 & $1.04-1.11$ & $<0.01$ & 1.07 & $1.03-1.11$ & $<0.01$ \\
\hline $\mathrm{CCl}$ (per unit) & 1.21 & $0.98-1.49$ & 0.01 & 1.19 & $0.95-1.48$ & 0.12 \\
\hline Hypertension (yes vs.no) & 1.34 & $0.74-2.42$ & 0.32 & & & \\
\hline Diabetes (yes vs.no) & 1.37 & $0.7-2.7$ & 0.34 & & & \\
\hline Proteinuria (yes vs. no) & 2.3 & $1.15-4.95$ & 0.01 & 2.4 & $1.02-5.65$ & 0.04 \\
\hline Tumor size (per cm) & 1.28 & $1.11-1.47$ & $<0.01$ & 1.05 & $0.87-1.27$ & 0.55 \\
\hline Baseline eGFR (per mL/min/1.73m²) & 1.01 & $0.99-1.02$ & 0.11 & 1.01 & 0.99-1.02 & 0.07 \\
\hline Ischemia time $\leq 20 \mathrm{~min}$. & Ref & & & Ref & & \\
\hline Ischemia time $>20 \mathrm{~min}$ & 4.63 & $2.13-10.4$ & $<0.01$ & 4.86 & $2.14-11.01$ & $<0.001$ \\
\hline EBL (per cc) & 1 & $1-1$ & 0.38 & & & \\
\hline IVF during surgery & 1 & $1-1$ & 0.57 & & & \\
\hline
\end{tabular}

$\mathbf{C I}=$ Confidential interval; $\mathbf{E B L}=$ Estimated Blood Loss; $\mathbf{O R}=$ Odds ratio

AKI is well established in the literature (32-34). In terms of patient factors, BMI was the only independent predictor of post-PN AKI. Obesity has been identified previously as a risk factor for AKI after surgery, consistent with our results (35). The pathophysiology of obesity-associated AKI is poorly understood but may be related to comorbidities, such as DM and HTN.

Our study suggests an increased risk of overall and major complications and 30-day readmissions following $\mathrm{PN}$ in patients with proteinuria. This association did not persist on multivariable logistic regression analysis, suggesting that comorbid conditions, which occur commonly together with proteinuria, may be responsible for this increased morbidity. Specifically, postoperative cardiovascular complications were more common in patients with proteinuria, consistent with prior studies that have shown an association between proteinuria and cardiovascular morbidity and mortality across di- vergent populations (36).

Our study is not without limitations. The retrospective design is a potential source of bias, and results from this single tertiary-care center cohort may not be generalizable. While multivariable analysis was used to adjust for known risk factors for postoperative AKI, additional unmeasured factors, for which we could not adjust, may have influenced the ultimate risk of AKI. Another limitation is that urine dipstick was used rather than 24-hour urinalysis for the assessment of proteinuria. Although a 24-hour urinalysis would be the ideal study for proteinuria, it is a more expensive and cumbersome test that would not be practical in all patients undergoing PN.

\section{CONCLUSIONS}

Our results indicate that preoperative proteinuria by urine dipstick is an independent pre- 
dictor of postoperative AKI after RPN in non-CKD patients. This test may be used to identify patients with occult renal dysfunction who are at increased risk for developing post-PN AKI.

\section{Compliance with Ethical Standards}

Dr. Jihad H. Kaouk is a consultant for Endocare/HealthTronics, and Intuitive. No competing financial interests exist for the other authors.

\section{ACKNOWLEDGEMENTS}

Dr. Önder Kara and Dr. Ercan Malkoç were supported by a grant for life expenses from TUBITAK: Technology and Innovation Support Programs, Directorate of the Scientific and Research Council of Turkey.

\section{CONFLICT OF INTEREST}

None declared.

\section{REFERENCES}

1. Campbell SC, Novick AC, Belldegrun A, Blute ML, Chow GK, Derweesh IH, et al. Guideline for management of the clinical T1 renal mass. J Urol. 2009;182:1271-9.

2. Sivarajan G, Taksler GB, Walter D, Gross CP, Sosa RE, Makarov DV. The Effect of the Diffusion of the Surgical Robot on the Hospital-level Utilization of Partial Nephrectomy. Med Care. 2015;53:71-8.

3. Liu JJ, Leppert JT, Maxwell BG, Panousis P, Chung BI. Trends and perioperative outcomes for laparoscopic and robotic nephrectomy using the National Surgical Quality Improvement Program (NSQIP) database. Urol Oncol. 2014;32:473-9.

4. Lane BR, Poggio ED, Herts BR, Novick AC, Campbell SC. Renal function assessment in the era of chronic kidney disease: renewed emphasis on renal function centered patient care. J Urol. 2009;182:435-43.

5. Lane BR, Fergany AF, Weight CJ, Campbell SC. Renal functional outcomes after partial nephrectomy with extended ischemic intervals are better than after radical nephrectomy. J Urol. 2010;184:1286-90.

6. Maurice MJ, Ramirez D, Malkoç E, Kara Ö, Nelson RJ, Caputo PA, et al. Predictors of Excisional Volume Loss in Partial Nephrectomy: Is There Still Room for Improvement? Eur Urol. 2016;70:413-5.
7. Chertow GM, Soroko SH, Paganini EP, Cho KC, Himmelfarb J, Ikizler TA, et al. Mortality after acute renal failure: models for prognostic stratification and risk adjustment. Kidney Int. 2006;70:1120-6.

8. Chawla LS, Eggers PW, Star RA, Kimmel PL. Acute kidney injury and chronic kidney disease as interconnected syndromes. N Engl J Med. 2014;371:58-66.

9. Go AS, Chertow GM, Fan D, McCulloch CE, Hsu CY. Chronic kidney disease and the risks of death, cardiovascular events, and hospitalization. N Engl J Med. 2004;351:1296-305. Erratum in: N Engl J Med. 2008;18:4.

10. Stevens PE, Levin A; Kidney Disease: Improving Global Outcomes Chronic Kidney Disease Guideline Development Work Group Members. Evaluation and management of chronic kidney disease: synopsis of the kidney disease: improving global outcomes 2012 clinical practice guideline. Ann Intern Med. 2013;158:825-30.

11. Lane BR, Demirjian S, Derweesh IH, Riedinger CB, Fergany AF, Campbell SC. Is all chronic kidney disease created equal? Curr Opin Urol. 2014;24:127-34.

12. Ognibene A, Grandi G, Lorubbio M, Rapi S, Salvadori B, Terreni A, ET AL.F. KDIGO 2012 Clinical Practice Guideline CKD classification rules out creatinine clearance 24 hour urine collection? Clin Biochem. 2016;49:85-9.

13. Schmid M, Abd-El-Barr AE, Gandaglia G, Sood A, Olugbade $\mathrm{K}$ Jr, Ruhotina N, et al. Predictors of 30-day acute kidney injury following radical and partial nephrectomy for renal cell carcinoma. Urol Oncol. 2014;32:1259-66.

14. Rajan S, Babazade R, Govindarajan SR, Pal R, You J, Mascha EJ, et al. Perioperative factors associated with acute kidney injury after partial nephrectomy. Br J Anaesth. 2016;116:70-6.

15. Schmid M, Krishna N, Ravi P, Meyer CP, Becker A, Dalela $D$, et al. Trends of acute kidney injury after radical or partial nephrectomy for renal cell carcinoma. Urol Oncol. 2016;34:293.

16. Bellomo R, Ronco C, Kellum JA, Mehta RL, Palevsky P; Acute Dialysis Quality Initiative workgroup. Acute renal failure definition, outcome measures, animal models, fluid therapy and information technology needs: the Second International Consensus Conference of the Acute Dialysis Quality Initiative (ADQI) Group. Crit Care. 2004;8:R204-12.

17. Clavien PA, Barkun J, de Oliveira ML, Vauthey JN, Dindo $D$, Schulick RD, et al. The Clavien-Dindo classification of surgical complications: five-year experience. Ann Surg. 2009;250:187-96.

18. Kutikov A, Uzzo RG. The R.E.N.A.L. nephrometry score: a comprehensive standardized system for quantitating renal tumor size, location and depth. J Urol. 2009;182:844-53. 
19. Levey AS, Bosch JP, Lewis JB, Greene T, Rogers N, Roth D. A more accurate method to estimate glomerular filtration rate from serum creatinine: a new prediction equation. Modification of Diet in Renal Disease Study Group. Ann Intern Med. 1999;130:461-70.

20. Levey AS, Coresh J, Balk E, Kausz AT, Levin A, Steffes MW, et al. National Kidney Foundation. National Kidney Foundation practice guidelines for chronic kidney disease: evaluation, classification, and stratification. Ann Intern Med. 2003;139:137-47. Erratum in: Ann Intern Med. 2003;139:605.

21. Kaouk JH, Khalifeh A, Hillyer S, Haber GP, Stein RJ, Autorino R. Robot-assisted laparoscopic partial nephrectomy: stepby-step contemporary technique and surgical outcomes at a single high-volume institution. Eur Urol. 2012;62:553-61.

22. Lameire NH, Bagga A, Cruz D, De Maeseneer J, Endre Z, Kellum JA, et al. Acute kidney injury: an increasing global concern. Lancet. 2013;382:170-9.

23. Hsu CY, Ordoñez JD, Chertow GM, Fan D, McCulloch CE, Go AS. The risk of acute renal failure in patients with chronic kidney disease. Kidney Int. 2008;74:101-7.

24. Zhang Z, Zhao J, Zabell J, Remer E, Li J, Campbell J, et al. Proteinuria in Patients Undergoing Renal Cancer Surgery: Impact on Overall Survival and Stability of Renal Function. Eur Urol Focus. 2016;2:616-22.

25. Tanagho YS, Kaouk JH, Allaf ME, Rogers CG, Stifelman MD, Kaczmarek BF, et al. Perioperative complications of robotassisted partial nephrectomy: analysis of 886 patients at 5 United States centers. Urology. 2013;81:573-9.

26. Huang TM, Wu VC, Young GH, Lin YF, Shiao CC, Wu PC, et al. National Taiwan University Hospital Study Group of Acute Renal Failure. Preoperative proteinuria predicts adverse renal outcomes after coronary artery bypass grafting. J Am Soc Nephrol. 2011;22:156-63.

27. Grams ME, Astor BC, Bash LD, Matsushita K, Wang Y, Coresh J. Albuminuria and estimated glomerular filtration rate independently associate with acute kidney injury. J Am Soc Nephrol. 2010;21:1757-64.

28. James MT, Hemmelgarn BR, Wiebe N, Pannu N, Manns BJ, Klarenbach SW, et al. Glomerular filtration rate, proteinuria, and the incidence and consequences of acute kidney injury: a cohort study. Lancet. 2010;376:2096-103.
29. Bhindi B, Lohse CM, Schulte PJ, Mason RJ, Cheville JC, Boorjian SA, et al. Predicting Renal Function Outcomes After Partial and Radical Nephrectomy. Eur Urol. 2018.

30. Krane LS, Heavner MG, Peyton C, Rague JT, Hemal AK. Association of Urine Dipstick Proteinuria and Postoperative Renal Function Following Robotic Partial Nephrectomy. J Endourol. 2016;30:532-6.

31. O'Donnell K, Tourojman M, Tobert CM, Kirmiz SW, Riedinger $\mathrm{CB}$, Demirjian S, Lane BR. Proteinuria is a Predictor of Renal Functional Decline in Patients with Kidney Cancer. J Urol. 2016;196:658-63.

32. Thompson RH, Lane BR, Lohse CM, Leibovich BC, Fergany $A$, Frank I, et al. Every minute counts when the renal hilum is clamped during partial nephrectomy. Eur Urol. 2010;58:3405.

33. Lane BR, Gill IS, Fergany AF, Larson BT, Campbell SC. Limited warm ischemia during elective partial nephrectomy has only a marginal impact on renal functional outcomes. J Urol. 2011;185:1598-603.

34. Becker F, Van Poppel H, Hakenberg OW, Stief C, Gill I, Guazzoni G, et al. Assessing the impact of ischaemia time during partial nephrectomy. Eur Urol. 2009;56:625-34.

35. Kelz RR, Reinke CE, Zubizarreta JR, Wang M, Saynisch P, Even-Shoshan 0, et al. Acute kidney injury, renal function, and the elderly obese surgical patient: a matched casecontrol study. Ann Surg. 2013;258:359-63.

36. Agrawal V, Marinescu V, Agarwal M, McCullough PA. Cardiovascular implications of proteinuria: an indicator of chronic kidney disease. Nat Rev Cardiol. 2009;6:301-11.

\section{Correspondence address:} Önder Kara, MD

Glickman Urological and Kidney Institute, Cleveland Clinic 9500 Euclid Avenue, Cleveland, Ohio, 44016, USA Fax: +1 216 636-4492 E-mail: onerkara@yahoo.com 